\title{
POLYMORPHIC LINKER HISTONE H1 VARIANTS IN BREEDING AND CONSERVATIVE DUCK POPULATIONS*
}

\author{
Andrzej Kowalski`, Jan Pałyga \\ Department of Biochemistry and Genetics, Institute of Biology, Jan Kochanowski University, \\ Świętokrzyska 15, 25-406 Kielce, Poland \\ •Corresponding author: a.kowalski@ujk.edu.pl
}

\begin{abstract}
A purpose of this study was to evaluate genetic diversity in duck populations based on polymorphic variants (H1.a, H1.b and H1.z) of linker histone H1. The study was performed using conservative brown-feathered Khaki Campbell (Kh1) and Orpington (Or) populations and white-feathered Pekin (P77) duck breeding line. While no significant distortion between both brown-feathered duck populations was noted $(\mathrm{P}>\mathbf{0 . 0 5})$, the allele frequencies at histone $\mathrm{H1}$ polymorphic loci were found to differ significantly between brown-feathered and white-feathered duck flocks $(\mathrm{P}<0.001)$. While the alleles $a^{1}, b^{1}$ and $z^{1}$ were detected in all three duck lines, the alleles $a^{2}$ and $b^{2}$ missed in the line P77 were found in the Kh1 and Or populations. A rare allele $z^{2}$ not detected in a homozygous state during screening our duck populations was found to occur only in heterozygous P77 duck individuals (z1z2). After a purpose mating of these heterozygous P77 birds, the homozygous individuals (z2) were obtained in their offspring. The uneven distribution of the alleles for polymorphic histone $\mathrm{H1}$ variants among duck populations seems to suggest that they are not functionally equivalent and, therefore, might have a differential influence on chromatin structure and/or function leading to line-specific phenotypic effects in duck.
\end{abstract}

Key words: duck, histone H1.a, histone H1.b, histone H1.z, polymorphism

Members of linker histone family (histones $\mathrm{H} 1$ and H5) are essential components of the DNA-protein complexes in eukaryotic chromatin. Unlike histones H2A, H2B, $\mathrm{H} 3$ and H4 that form nucleosome core particles around which DNA is wrapped, histone $\mathrm{H} 1$ is located over the nucleosomal dyad axis to bind nucleosomal DNA segment to DNA linker entering and/or leaving the nucleosome core (Ramakrishnan, 1997; Travers, 1999; Pachov et al., 2011). The linker histones help fold 10-nm nucleosomal arrays into 30-nm compacted structures through interaction of their $\mathrm{N}$-terminal and central globular domains with the nucleosomal DNA and their C-terminal domains with the linker DNA (Caterino and Hayes, 2011). Acting as components promoting condensed chromatin state, the H1 histones may simultaneously affect gene expres-

*This study was supported by statutory activity of Jan Kochanowski University, project No. 612459.00 . 
sion through hindering the access of regulatory factors to the DNA (Juan et al., 1997; Kim et al., 2008). Apart from structural and repressive functions, the $\mathrm{H} 1$ histones influence various cellular processes by interacting with partner proteins. For example, histone $\mathrm{H} 1$ influences muscle cell differentiation by interaction with $M y o D$ transcription factor Msx 1, tumorigenicity by interactions with tumor suppressor lysyl oxidase (LOX) and apoptosis by interaction with apoptotic endonuclease DFF40 (McBryant et al., 2010). Histone H1-mediated dynamic processes depend on the presence of low and high affinity $\mathrm{H} 1$ variant populations with different binding properties exemplified by the presence of rapidly diffusing, weakly and strongly bound, or stably bound protein pools in the euchromatin and heterochromatin regions (Raghuram et al., 2009). The histone H1 multifunctionality is largely determined by its specific components, primary sequence variants or subtypes, expressed in a variable number and amount in different tissues and taxons (Jerzmanowski, 2004). In addition to some alterations in N-terminal sequences, these variants differ in their intrinsically disordered C-terminal domains (McBryant and Hansen, 2012) which are usually targeted for posttranslational modifications (Godde and Ura, 2008) and frequently harbour genetic variations (Pałyga et al., 2000; Kowalski et al., $2011 \mathrm{a}, \mathrm{b})$.

Previously, a polymorphic heterogeneity of erythrocyte $\mathrm{H} 1$ histone subtypes H1.a, H1.b and H1.z has been found in duck (Kowalski et al., 1998; Pałyga et al., 1993; Pałyga et al., 2000) and quail (Pałyga, 1998 a). The present study was aimed at characterizing alterations in allele frequencies for the polymorphic histone H1 subtypes (H1.a, H1.b and H1.z) among two conservative (brown-feathered - Kh1 and Or) and one breeding (white-feathered - P77) duck line. We have found significant differences in the occurrence of alleles $a^{1}, b^{1}$ and $z^{1}$ among all tested duck populations and a lack of alleles $a^{2}$ and $b^{2}$ in P77 line. Therefore, we believe that the histone $\mathrm{H} 1$ polymorphic variants might specifically affect certain physiological traits in duck by influencing chromatin structure and/or function.

\section{Material and methods}

Duck stocks used in this study were housed at the Experimental Station (Dworzyska near Poznań) of the National Research Institute of Animal Production, Balice near Kraków, Poland. Initially screened Khaki Campbell (Kh1), Orpington (Or) and Pekin P77 (P77) populations containing 52, 49 and 56 duck individuals, respectively, were shown to accommodate individuals representing almost all homozygous phenotypes for polymorphic histone variants H1.a, H1.b and H1.z except histone H1.z2 (phenotype z2). To obtain the missing homozygote $z 2$, four heterozygous (z1z2) females and two heterozygous males were chosen for purpose mating at the end of normal breeding season. A distribution of histone H1 phenotypes was analysed in 21 and 28 ducklings representing the progeny from $\mathrm{b} 1 \mathrm{~b} 3 / \mathrm{z} 1 \mathrm{z} 2$ and $\mathrm{a} 1 \mathrm{a} 2 / \mathrm{b} 1 \mathrm{~b} 2$ dihybrid parents, respectively; the latter mating served as a control. Blood from duck individuals, as well as from parental birds and their offspring at the age of 4-6 weeks, was 
collected separately from a wing vein into a cold SSC solution $(0.15 \mathrm{M} \mathrm{NaCl}$ and $0.015 \mathrm{M}$ sodium citrate) supplemented with $1 \mathrm{mM}$ phenylmethylsulfonyl fluoride (PMSF) and after washing several times with the above solution was used as a source of erythrocytes for histone $\mathrm{H} 1$ isolation.

The lysis of erythrocytes in the presence of saponin to obtain crude nuclear pellet and subsequent perchloric acid extraction of histone $\mathrm{H} 1$ were performed as described by Neelin et al. (1995). Histone H1 proteins were analysed by electrophoretic separation in a two dimensional polyacrylamide gel which combined acetic acid-urea polyacrylamide gel (AU-PAGE) resolution in the first dimension with sodium dodecyl sulfate polyacrylamide gel (SDS-PAGE) electrophoresis in the second dimension as described by Kowalski and Pałyga (2012).

A fit to the Hardy-Weinberg equilibrium was tested by chi-square $\left(\chi^{2}\right)$ goodnessof-fit test. The probability less than $0.05(\mathrm{P}<0.05)$ was regarded as statistically significant.

\section{Results}

In this work, electrophoretic screenings in one- and two-dimension polyacrylamide gels have been conducted to determine a simultaneous distribution of polymorphisms for erythrocyte histone H1 subtypes H1.a (Kowalski et al., 1998), H1.b (Pałyga et al., 2000) and H1.z (Pałyga et al., 1993) in three duck populations. The histones H1.a (Figure 1) and H1.z (Figure 2) were found to contain two allelic variants each differently migrating in AU-PAGE and SDS-PAGE, respectively. The isoforms H1.a1 and H1.a2 presumably differed in a net charge and the isoforms H1.z1 and H1.z2 possessed distinct apparent molecular weights. The histone H1.b (Figure 2) was composed of three allelic variants of which similarly charged isoforms H1.b1 and H1.b3 differed in apparent molecular weights from the isoform H1.b2.

Pronounced differences in the distribution of histone $\mathrm{H} 1$ phenotypes in conservative (Kh1 and Or) and breeding (P77) duck lines presented in Table 1 and 2 were associated with a lack of the homozygous phenotypes a2, b2 and z2 and heterozygous phenotypes a1a2, b1b2 and b2b3 in the line P77. Moreover, a homozygous phenotype b3 and heterozygous phenotype z1z2 were detected among 15 and 14 individuals, respectively, in the line P77 only. Because of a total lack of homozygous ducks with phenotype z2, the heterozygous birds z1z2 represented a sole source of the allele $z^{2}$.

A comparison of histone $\mathrm{H} 1$ allele frequencies in Kh1, Or and P77 duck populations indicated no difference $(\mathrm{P}>0.5)$ between brown feathered duck flocks (Kh1 and Or), and a significant disparity $(\mathrm{P}<0.001)$ between each of them and breeding (P77) line (Table 2). The chi-square goodness-of-fit test $\left(\chi^{2}\right)$ (Table 3 ) confirmed no violation of Hardy-Weinberg equilibrium except locus H1.a in Kh1 population for which $\chi^{2}=3.92$ corresponded to the probability of 0.048 that was only a slightly below the limit value of 0.05 . The fixation indices of Wright F-statistics specifying inter-individual $\left(\mathrm{F}_{\mathrm{IS}}\right)$, subpopulation $\left(\mathrm{F}_{\mathrm{ST}}\right)$ and the total population $\left(\mathrm{F}_{\mathrm{IT}}\right)$ 
allelic correlations were applied to quantify genetic variation between duck strains at each polymorphic $\mathrm{H} 1$ histone locus (Table 3). A within-line $\left(\mathrm{F}_{\mathrm{IS}} \mathrm{Kh} 1=-0.24\right.$, Or $=-0.1$ and $\mathrm{P} 77=-0.14)$ and between-line $\left(\mathrm{F}_{\mathrm{IT}} \mathrm{Kh} 1=-0.072\right.$, Or $=0.07$ and $\mathrm{P} 77=-0.12)$ excess of heterozygous individuals and moderate degree of genetic diversity $\left(\mathrm{F}_{\mathrm{ST}} \mathrm{Kh} 1=0.135\right.$, Or $=0.157$ and $\left.\mathrm{P} 77=0.1\right)$ were observed.
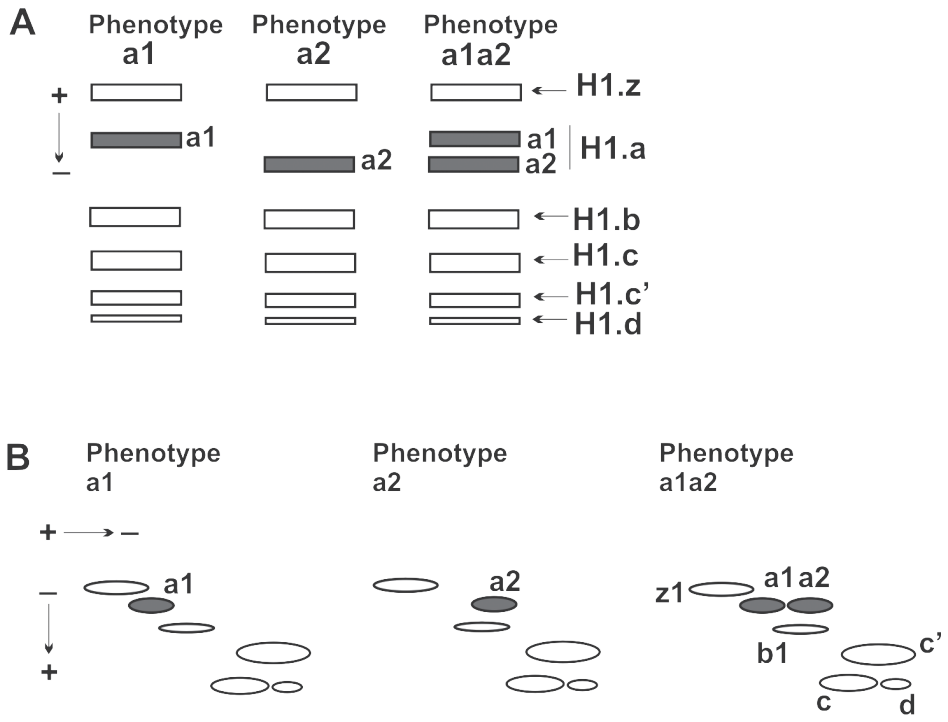

Figure 1. A scheme of electrophoretic patterns of duck erythrocyte histone H1.a. (Panel A), Histone $\mathrm{H} 1$ was resolved in the first dimension in AU-PAGE into an array of subtypes H1.z, H1.b, H1.c, H1, $\mathrm{c}^{\prime}$ and H1.d (white rectangles), and histone H1.a isoforms (grey rectangles) with differential localization in the gel. Two allelic variants, slower migrating H1.a1 and faster moving H1.a2, formed homozygous phenotypes a1 and a2, respectively, and together contributed to a heterozygous phenotype a1a2. (Panel $B$ ), Histone $\mathrm{H} 1$ subtypes resolved in a two-dimension polyacrylamide gel. In comparison to a stable in-gel localization of allelic isoforms H1.z1 and H1.b1 and remaining histone H1 subtypes (H1.c, H1, ${ }^{\prime}$ and H1.d) migrating further away (white ovals), the allelic isoforms of histone H1.a (grey ovals) are shifted either toward histone H1.z1 (isoform H1.a1) or histone H1.b1 (isoform H1.a2). The pattern of the histone H1.a allelic isoform migration reflects differences in their net charges rather than molecular weights

The disparities in the distribution of histone $\mathrm{H} 1$ phenotypes were brought about by a lack of some phenotypes in the screened duck lines (Tables 1 and 2). In addition, the phenotype $\mathrm{z} 2$ was totally absent in all tested duck populations. The individuals possessing phenotype z1z2 (14 birds only in P77 population), which constituted less than $10 \%$ of whole duck population (Table 1), were used to set up genetic crossings to obtain the missing homozygous phenotype $\mathrm{z} 2$ in their progeny. Four dihybrid fe- 
males (b1b3/z1z2) and two dihybrid males (b1b3/z1z2) were chosen to establish two independent matings (two females per one male) at the end of the breeding season. Out of 23 individuals in the offspring that survived to the age of 4-6 weeks, 21 ducklings were analysed. Besides homozygotes z1 (11 individuals) and heterozygotes z1z2 (4 individuals), 6 ducklings were unequivocally identified as homozygotes z2 (Table 4). Thus, the mating of heterozygous parents is an appropriate method for obtaining homozygous individuals in the progeny which otherwise are missed in the general population. However, a significant disproportion in the ratio of both H1.b and H1.z phenotypes was noticed, presumably due to a small size of the resulting offspring. In addition, two dihybrid (a1a2/b1b2) matings, each separately for Kh1 and Or ducks, was performed as a control. In these families despite small size of each progeny, the number of histone H1.a and histone H1.b phenotypes did not deviate from the expected 1:2:1 ratio (Table 5).
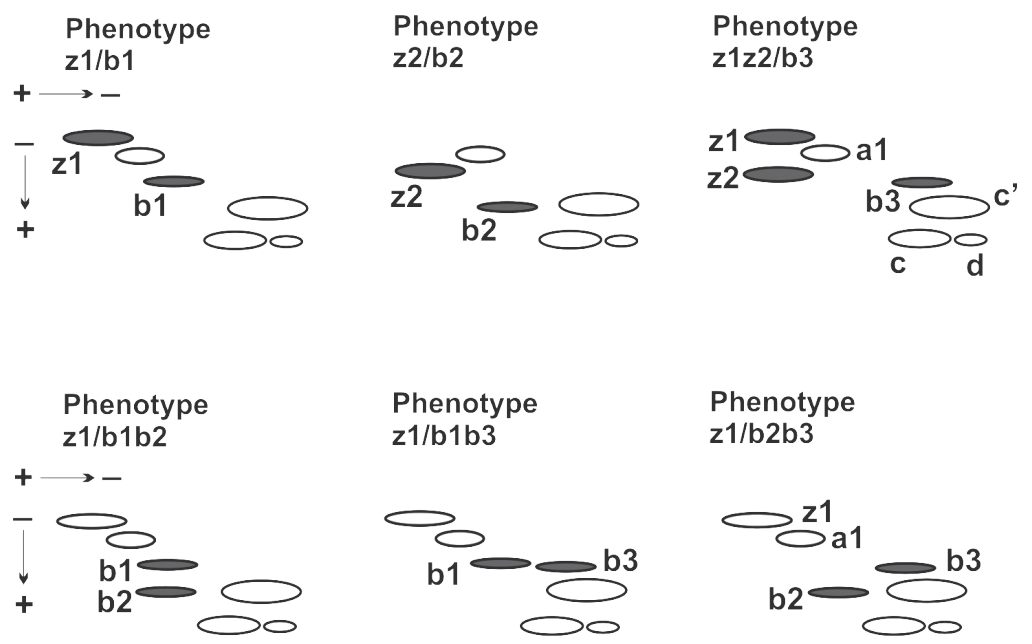

Figure 2. A scheme of two-dimensional electrophoretic patterns of duck erythrocyte histone H1.z and histone H1.b. While no differences in the electrophoretic migration of both histone H1.z and histone H1.b were detected in the first dimension AU-PAGE, three phenotypes (z1, z1 and z1z2) of histone H1. $\mathrm{z}$ containing allelic variants $\mathrm{H} 1 . \mathrm{z} 1$ and/or $\mathrm{H} 1 . \mathrm{z} 2$ and six phenotypes (b1, b2, b3, b1b2, b1b3 and b2b3) of histone H1.b formed by allelic variants H1.b1, H1.b2 and H1.b3 were detected in the second dimension SDS-PAGE. There are evident differences in the rate of electrophoretic migration between histones H1.z1 and H1.z2 (grey ovals) in relation to histone H1.a1 (white oval). The histone H1.b isoforms (grey ovals) move either slower (isoform H1.b1) or faster (isoform H1.b2) with respect to a stably migrating histone H1.c', or with a similar rate as H1.b1 but further to the right (variant H1.b3). Thus, the isoforms H1.b1 and H1.b3 have similar molecular weights but differ in net charges while the isoform H1.b2 differs in molecular weight both from H1.b1 and H1.b3 


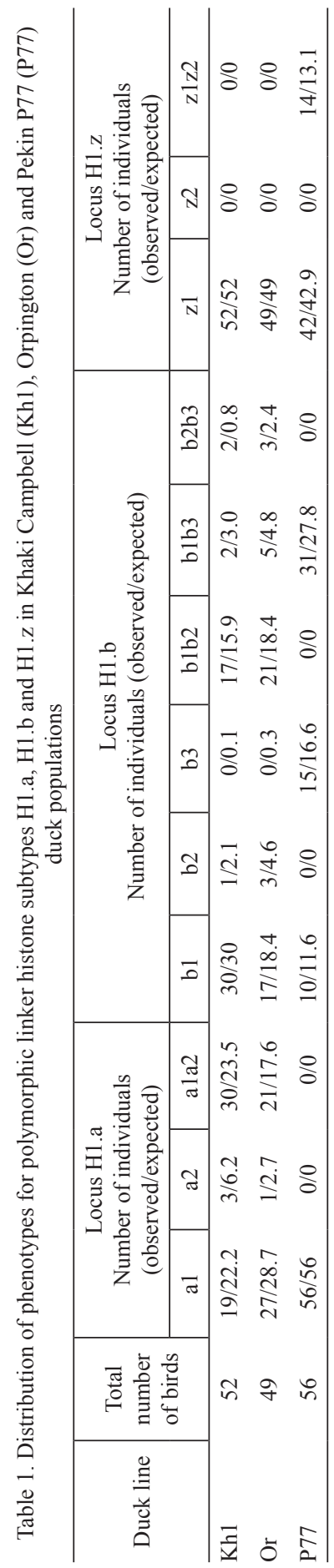


Table 2. Frequency of phenotypes and alleles for polymorphic H1 histone variants in Khaki Campbell (Kh1), Orpington (Or) and Pekin P77 (P77) duck populations

\begin{tabular}{|c|c|c|c|c|c|}
\hline \multirow{2}{*}{ Locus } & \multirow{2}{*}{\multicolumn{2}{|c|}{$\begin{array}{c}\text { Frequency of phenotypes } \\
\text { and alleles }\end{array}$}} & \multicolumn{3}{|c|}{ Duck line } \\
\hline & & & Kh1 & Or & P77 \\
\hline \multirow[t]{5}{*}{ H1.a } & \multirow{3}{*}{$\begin{array}{l}\text { Frequency of phenotypes } \\
\text { (observed/expected) }\end{array}$} & al & $0.365 / 0.428$ & $0.55 / 0.585$ & $1 / 1$ \\
\hline & & $\mathrm{a} 2$ & $0.058 / 0.119$ & $0.02 / 0.055$ & $0 / 0$ \\
\hline & & a1a2 & $0.577 / 0.452$ & $0.429 / 0.36$ & $0 / 0$ \\
\hline & \multirow[t]{2}{*}{ Frequency of alleles ${ }^{a}$} & $a^{l}$ & 0.654 & 0.765 & 1 \\
\hline & & $a^{2}$ & 0.346 & 0.235 & 0 \\
\hline \multirow[t]{9}{*}{ H1.b } & \multirow{6}{*}{$\begin{array}{l}\text { Frequency of phenotypes } \\
\text { (observed/expected) }\end{array}$} & b1 & $0.578 / 0.578$ & $0.347 / 0.374$ & $0.179 / 0.208$ \\
\hline & & b2 & $0.019 / 0.040$ & $0.061 / 0.094$ & $0 / 0$ \\
\hline & & b3 & $0 / 0.001$ & $0 / 0.007$ & $0.268 / 0.296$ \\
\hline & & b1b2 & $0.327 / 0.307$ & $0.429 / 0.375$ & $0 / 0$ \\
\hline & & b1b3 & $0.038 / 0.058$ & $0.102 / 0.1$ & $0.553 / 0.496$ \\
\hline & & b2b3 & $0.038 / 0.015$ & $0.061 / 0.05$ & $0 / 0$ \\
\hline & \multirow[t]{3}{*}{ Frequency of alleles ${ }^{b}$} & $b^{l}$ & 0.76 & 0.612 & 0.456 \\
\hline & & $b^{2}$ & 0.202 & 0.306 & 0 \\
\hline & & $b^{3}$ & 0.038 & 0.082 & 0.544 \\
\hline \multirow[t]{5}{*}{$\mathrm{H} 1 . \mathrm{z}$} & \multirow{3}{*}{$\begin{array}{l}\text { Frequency of phenotypes } \\
\text { (observed/expected) }\end{array}$} & $\mathrm{z} 1$ & $1 / 1$ & $1 / 1$ & $0.75 / 0.77$ \\
\hline & & $\mathrm{z} 2$ & $0 / 0$ & $0 / 0$ & $0 / 0$ \\
\hline & & $\mathrm{z} 1 \mathrm{z} 2$ & $0 / 0$ & $0 / 0$ & $0.25 / 0.22$ \\
\hline & \multirow[t]{2}{*}{ Frequency of alleles ${ }^{z}$} & $z^{l}$ & 1 & 1 & 0.875 \\
\hline & & $z^{2}$ & 0 & 0 & 0.125 \\
\hline
\end{tabular}

$\mathrm{a}, \mathrm{b}, \mathrm{z}$ - significant differences in the allele frequencies between Kh1-P77 $(\mathrm{P}<0.001)$ and Or-P77 $(\mathrm{P}<0.001)$.

Table 3. Chi-square test of Hardy-Weinberg equilibrium and parameters of genetic diversity for duck histone $\mathrm{H} 1$ polymorphic variants. $\mathrm{H}_{\mathrm{O}}$ - observed heterozygosity, $\mathrm{H}_{\mathrm{E}}$ - expected heterozygosity, $\mathrm{H}_{\mathrm{I}}-$ genetic differentiation within individuals in population, $\mathrm{H}_{\mathrm{S}}-$ genetic differentiation within population, $\mathrm{H}_{\mathrm{T}}$ - genetic differentiation in total population and fixation indices $\left(\mathrm{F}_{\mathrm{IS}}, \mathrm{F}_{\mathrm{ST}}\right.$ and $\left.\mathrm{F}_{\mathrm{IT}}\right)$ of Wright's F-statistics for Khaki Campbell (Kh1), Orpington (Or) and Pekin P77 (P77) duck populations

\begin{tabular}{|c|c|c|c|c|c|c|c|c|c|c|c|}
\hline $\begin{array}{c}\text { Duck } \\
\text { population }\end{array}$ & Locus & $\chi^{2} / p$ & $\mathrm{H}_{\mathrm{O}}$ & $\mathrm{H}_{\mathrm{E}}$ & Locus & $\mathrm{H}_{\mathrm{I}}$ & $\mathrm{H}_{\mathrm{s}}$ & $\mathrm{H}_{\mathrm{T}}$ & $\mathrm{F}_{\text {IS }}$ & $\mathrm{F}_{\mathrm{ST}}$ & $\mathrm{F}_{\mathrm{IT}}$ \\
\hline \multirow[t]{3}{*}{ Kh1 } & H1.a & $3.92 / 0.048 \mathrm{a}$ & 0.577 & 0.454 & H1.a & 0.325 & 0.262 & 0.303 & -0.24 & 0.135 & -0.072 \\
\hline & H1.b & $2.91 / 0.713 \mathrm{~b}$ & 0.403 & 0.381 & & & & & & & \\
\hline & H1.z & 0 & 0 & 0 & & & & & & & \\
\hline \multirow[t]{3}{*}{ Or } & H1.a & $1.77 / 0.183 \mathrm{a}$ & 0.429 & 0.36 & H1.b & 0.51 & 0.467 & 0.554 & -0.1 & 0.157 & 0.07 \\
\hline & H1.b & $1.48 / 0.915 \mathrm{~b}$ & 0.591 & 0.526 & & & & & & & \\
\hline & H1.z & 0 & 0 & 0 & & & & & & & \\
\hline \multirow[t]{3}{*}{ P77 } & H1.a & 0 & 0 & 0 & H1.z & 0.08 & 0.078 & 0.087 & -0.14 & 0.1 & -0.12 \\
\hline & H1.b & $0.75 / 0.979 b$ & 0.554 & 0.496 & & & & & & & \\
\hline & H1.z & $0.08 / 0.78 \mathrm{a}$ & 0.25 & 0.219 & & & & & & & \\
\hline
\end{tabular}


Table 4. A distribution of histone H1.b and H1.z phenotypes in progeny of Pekin P77 dihybrid parents (b1b3/z1z2)

\begin{tabular}{c|c|c|c}
\hline Locus & $\begin{array}{c}\text { Total number of individuals } \\
\text { in progeny }\end{array}$ & Phenotype & $\begin{array}{c}\text { Number of individuals } \\
\text { (observed/expected) }\end{array}$ \\
\hline H1.b & 21 & $\mathrm{~b} 1$ & $6 / 5.25$ \\
& & $\mathrm{~b} 3$ & $11 / 5.25 \mathrm{a}$ \\
H1.z & \multirow{2}{*}{21} & $\mathrm{~b} 1 \mathrm{~b} 3$ & $4 / 10.5 \mathrm{a}$ \\
& & $\mathrm{z} 1$ & $11 / 5.25 \mathrm{a}$ \\
& $\mathrm{z} 2$ & $6 / 5.25$ \\
& $\mathrm{z} 1 \mathrm{z} 2$ & $4 / 10.5 \mathrm{a}$ \\
\hline
\end{tabular}

$\mathrm{a}=\mathrm{P}<0.05$.

Table 5. A distribution of histone H1.a and H1.b phenotypes in progeny of the control matings of Khaki Campbell (Kh1) and Orpington (Or) dihybrid parents (a1a2/b1b2). Because of a lack of deviation from the expected number of individuals in progeny in each family, the merged data (Kh1+Or) were provided

\begin{tabular}{c|c|c|c}
\hline Locus & $\begin{array}{c}\text { Total number of birds in } \\
\text { progeny }\end{array}$ & Phenotype & $\begin{array}{c}\text { Number of individuals } \\
\text { (observed/expected) }\end{array}$ \\
\hline H1.a & 28 & a1 & $6 / 7.5$ \\
& & a2 & $7 / 7.5$ \\
H1.b & \multirow{2}{*}{28} & ala2 & $15 / 14$ \\
& & b1 & $7 / 7.5$ \\
& & b2 & $6 / 7.5$ \\
& & b1b2 & $15 / 14$ \\
\hline
\end{tabular}

\section{Discussion}

The array of avian erythrocyte histone $\mathrm{H} 1$ is usually composed of six or seven subtypes (Pałyga, 1991), from which just one, H1.c', has not been recognized as polymorphic. The remaining H1 subtypes could be polymorphic due to the occurrence of allelic variants possessing disparate net charges and/or molecular weights as reflected by their differential migration in the polyacrylamide gels. Apart from allelic isoforms of duck histone variants H1.a, H1.b and H1.z differing in molecular weights (H1.z1 and H1.z2, or H1.b1, H1.b3 and H1.b2) or charge (H1.a1 and H1.a2 or H1.b1 and H1.b3) presented in this work, the polymorphic variants of other histone H1 subtypes were identified in some bird species. For example, grey partridge histone H1.a' (Kowalski et al., 2008) was resolved into electromorphs differing in molecular weights while histone H1.c was composed of isoforms possessing either distinct net charges in pheasant (Kowalski et al., 2010) or molecular weights in guinea fowl (Kowalski et al., 2011 b). Recently identified polymorphism of histone H1.d in quail erythrocytes (Kowalski and Pałyga, submitted) has been associated with quantitative changes in the amount of protein between allelic isoforms, judging from distinct and reproducible levels of spot intensities (high, intermediate and low).

The histone $\mathrm{H} 1$ polymorphic variation was often specific for different avian breeds or populations. For example, heterozygous individuals b1b2 and c1c2 were 
detected only in the black-feathered guinea fowl population whereas no such individual was revealed in the white-feathered birds (Kowalski et al., $2011 \mathrm{~b}$ ). The polymorphic histone H1.a was represented by phenotypes a1 and a1a2 in several chicken flocks (Górnicka-Michalska et al., 2006). The missing third phenotype a2 appeared only in a progeny of purpose-mated chicken among which 16 chicks with phenotype a2 out of 67 individuals were found and all phenotypes (a1, a2 and a1a2) in the progeny conformed to the expected Mendelian ratio (1:2:1). A significant distortion in the ratio of histone H1.z phenotypes among the P77 ducklings in our work might be caused by a relatively small size of the progeny flock. Since allele $z^{2}$ was found at low frequencies (from 0.02 to 0.06) among five duck lines screened (Pałyga et al., 1993), it seems that this allele might be associated with some unfavourable breeding trait(s) and thus might be eliminated from the population following breeding selection. Nevertheless, the results of crosses in both chicken (Górnicka-Michalska et al., 2006) and duck (this work) support the possibility of obtaining the missing phenotype in the offspring after crossing the heterozygous parents on purpose.

A considerable disproportion in the distribution of histone $\mathrm{H} 1$ alleles in different populations (Pałyga et al., 2000) as well during selection for a particular trait (Pałyga, 1998 b) seem to suggest that members of this chromatin protein family may exert allele-specific functional effects. The presence of particular histone $\mathrm{H} 1$ isoform may lead to changes in histone $\mathrm{H} 1$ interaction with DNA and/or protein regulators in chromatin milieu. Thus, the possible explanation of our results is that the histone $\mathrm{H} 1$ alleles, such as $a^{1}$ and $a^{2}$ or $z^{1}$ and $z^{2}$ in P77 duck line, are not functionally equivalent and might produce differential effects on duck viability and/or performance through changes in chromatin processes including gene transcription.

\section{Acknowledgement}

We are indebted to Professor Juliusz Książkiewicz for allowing us to collect blood samples from his duck flocks and invaluable contribution to rearing purposemated duck families.

\section{References}

C a t e r in o T.L, H a y e s J.J. (2011). Structure of the H1 C-terminal domain and function in chromatin condensation. Biochem. Cell Biol., 89: 35-44.

G o d d e J.S., U r a K. (2008). Cracking the enigmatic linker histone code. J. Biochem., 143: $287-293$.

Górnicka-M i chalska E., Pałyga J., Kowalski A., Cywa-Benko K. (2006). Sequence variants of chicken linker histone H1.a. FEBS J., 273: 1240-1250.

J e r z m a n ow s ki A. (2004). The linker histones. (In:) Chromatin Structure and Dynamics: State-ofthe-Art. Zlatanova J., Leuba S.H. (eds). Elsevier Amsterdam/New York, pp. 75-102.

J u a n L.J., U t l e y R.T., Vig n a li M., B o h m L., W o r k m a n J.L. (1997). H1-mediated repression of transcription factor binding to a stably positioned nucleosome. J. Biol. Chem., 272: 3635-3640.

K i m K., Choi J., H e o K., K i m H., Levens D., Kohno K., Johns on E.M., B rock H.W., A n W. (2008). Isolation and characterization of a novel H1.2 complex that acts as a repressor of p53-mediated transcription. J. Biol. Chem., 283: 9113-9126.

K o w a ls k i A., P ały g a J. (2012). High-resolution two-dimensional polyacrylamide gel electrophoresis: a tool for identification of polymorphic and modified linker histone components. (in) Gel Electrophoresis - Principles and Basics. (Magdeldin S. ed.). InTech, Rijeka, Croatia, pp. 117-136. 
Kowalski A., Pałyga J., Górnicka-Michalska E. (2008). Polymorphic isoforms of erythrocyte histone H1.a' in a grey partridge population. J. Agrobiol., 25: 125-127.

Kowalski A., Pałyga J., Górnicka-Michalska E. (2011 a). Linker histone H1.b is polymorphic in grey partridge (Perdix perdix). Z. Naturforsch., 66c: 296-304.

Kowalski A., Pały ga J., Górnicka-Michalska E. (2011 b). Two polymorphic linker histone loci in guinea fowl erythrocytes. C. R. Biol., 334: 6-12.

Kowalski A., Pałyga J., Górnicka-Michalska E., Bernacki Z., Adamski M. (2010). Phenotypic variation of erythrocyte linker histone H1.c in a pheasant (Phasianus colchicus L.) population. Genet. Mol. Biol., 33: 475-478.

Kowalski A., Pałyga J., Górnicka-Michalska E., Krajewska W.M. (1998). Allelic polymorphism of histone H1.a in duck erythrocytes. Biochem. Genet., 36: 183-191.

M c B ryant S.J., Hans en J.C. (2012). Dynamic fuzziness during linker histone action. Adv. Exp. Med. Biol., 725: 15-26.

M c B r y a n t S.J., L u X., H a n s e n J.C. (2010). Multifunctionality of the linker histones: an emerging role for protein-protein interactions. Cell Res., 20: 519-528.

N e e 1 i n J.M., N e e 1 in E.M., L in d s a y D.W., P ały g a J., N i c hols C.R., Ch en g K.M. (1995). The occurence of a mutant dimerizable histone H5 in Japanese quail erythrocytes. Genome, 38 : 982-990.

P a ch ov G.V., G a b d o u 11 in e R.R., Wa d e R.C. (2011). On the structure and dynamics of the complex of the nucleosome and the linker histone. Nucleic Acids Res., 39: 5255-5263.

P a ły g a J. (1991). A comparison of the histone H1 complements of avian erythrocytes. Int. J. Biochem., 23: 845-849.

Pałyga J. (1998 a). Genes for polymorphic H1 histones are linked in the Japanese quail genome. Biochem. Genet., 36: 93-103.

P ały g a J. (1998 b). Distribution of allelic forms of erythrocyte H1 histones in Japanese quail populations divergently selected for amount of weight loss after transient starvation. Biochem. Genet., 36: 79-92.

Pałyga J., Górnicka-Michalska E., Kowalski A. (1993). Genetic polymorphism of histone H1.z in duck erythrocytes. Biochem. J., 294: 859-863.

Pałyga J., Górnicka-Michalska E., Kowalski A., Ks iążkiewicz J. (2000). Natural allelic variation of duck erythrocyte histone H1.b. Int. J. Biochem. Cell Biol., 32: 665-675.

Raghuram N., Carrero G., Th'ng J., Hendzel M.J. (2009). Molecular dynamics of histone H1. Biochem. Cell. Biol., 87: 189-206.

R a makrishnan V. (1997). Histone structure and the organization of the nucleosome. Ann. Rev. Biophys. Biomol. Struct., 26: 83-112.

Travers A. (1999). The location of the linker histone on the nucleosome. Trends Biochem. Sci., 24: 4-7.

Accepted for printing 19 IV 2013 